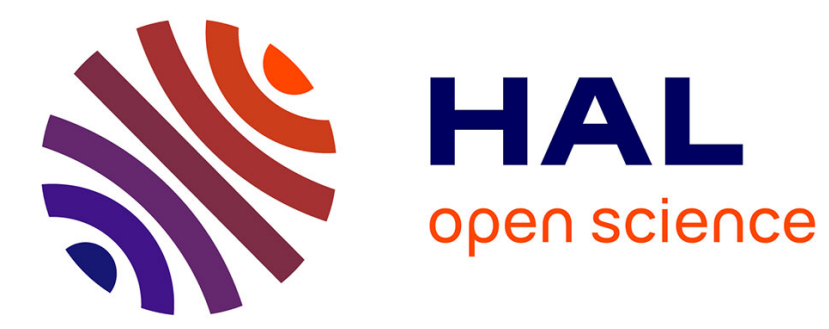

\title{
Facial mimicry in the congenitally blind
}

P Arias, Caren Bellmann, Jean-Julien Aucouturier

\section{To cite this version:}

P Arias, Caren Bellmann, Jean-Julien Aucouturier. Facial mimicry in the congenitally blind. Current Biology - CB, 2021, 31 (19), pp.1112 - 1114. hal-03455053

\section{HAL Id: hal-03455053 https://hal.science/hal-03455053}

Submitted on 26 Jan 2022

HAL is a multi-disciplinary open access archive for the deposit and dissemination of scientific research documents, whether they are published or not. The documents may come from teaching and research institutions in France or abroad, or from public or private research centers.
L'archive ouverte pluridisciplinaire HAL, est destinée au dépôt et à la diffusion de documents scientifiques de niveau recherche, publiés ou non, émanant des établissements d'enseignement et de recherche français ou étrangers, des laboratoires publics ou privés. 


\section{Magazine}

\section{Correspondence}

\section{Facial mimicry in the congenitally blind}

\author{
Pablo Arias ${ }^{1,2,5, *}$, Caren Bellmann ${ }^{3}$,
} and Jean-Julien Aucouturier ${ }^{1,4}$

Imitation is one of the core building blocks of human social cognition, supporting capacities as diverse as empathy, social learning, and knowledge acquisition ${ }^{1}$. Newborns' ability to match others' motor acts, while quite limited initially, drastically improves during the first months of development ${ }^{2}$. Of notable importance to human sociality is our tendency to rapidly mimic facial expressions of emotion. Facial mimicry develops around six months of age ${ }^{3}$, but because of its late emergence, the factors supporting its development are relatively unknown. One possibility is that the development of facial mimicry depends on seeing emotional imitative behavior in others ${ }^{4}$. Alternatively, the drive to imitate facial expressions of emotion may be independent of visual learning and be supported by modality-general processes. Here we report evidence for the latter, by showing that congenitally blind participants facially imitate smiles heard in speech, despite having never seen a facial expression.

To investigate whether facial mimicry develops independently from visual learning, we studied how blind participants respond to the acoustic cues generated by a smiling facial expression while speaking ${ }^{5}$. To control these cues in experimental stimuli, we used a digital audio processing algorithm that simulates how the contraction of zygomatics shifts spectral resonances - formants - in the voice ${ }^{6}$ (Figure $\left.1 \mathrm{~A}\right)$, while leaving all other characteristics of emotional speech, such as content, or intonation, unchanged. Using this tool, we generated 120 spoken-sentence stimuli, by transforming 40 sentences in three matched conditions: neutral, smile (increased lip stretching) and unsmile (decreased lip stretching). In these stimuli, the transformation had the notable effect of selectively shifting the mean frequency of the first two vocal formants either positively (smile effect) or negatively ('unsmile' effect; $p<0.0001$, Figure 1B; Supplemental Information).

Using these stimuli, we conducted an electromyography (EMG) experiment to study facial mimicry in the blind. We asked $\mathrm{N}=14$ blind participants - five congenital, six early, three late; all purely ocular, non-cortical impairments - to judge the smiliness of the generated stimuli in two successive tasks: a rating task (continuous rating scale) and a detection task (go/no go). In both tasks, participants rated the smiled and unsmiled versions of all sentences, while we recorded their zygomatic major (used to smile) and corrugator supercili (used to frown) muscles with facial EMG (see Supplemental Information for detailed experimental procedures).

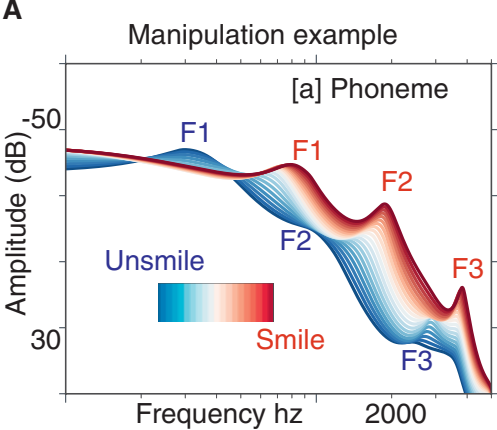

B

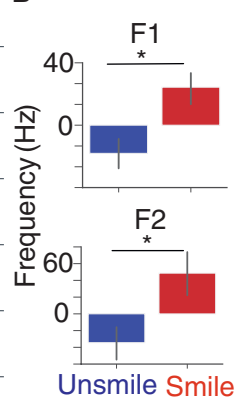

C

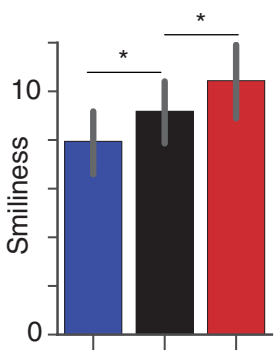

Unsmile Neutral Smile id 9

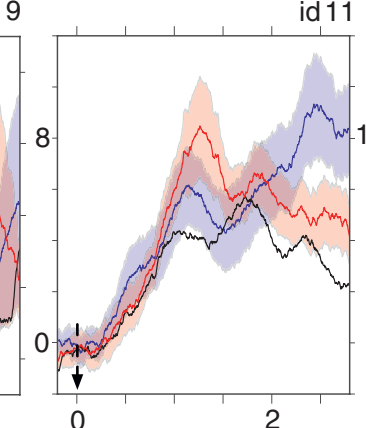

Detection task

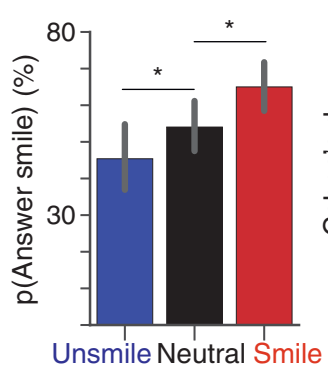

D

Smile decoding accuracy
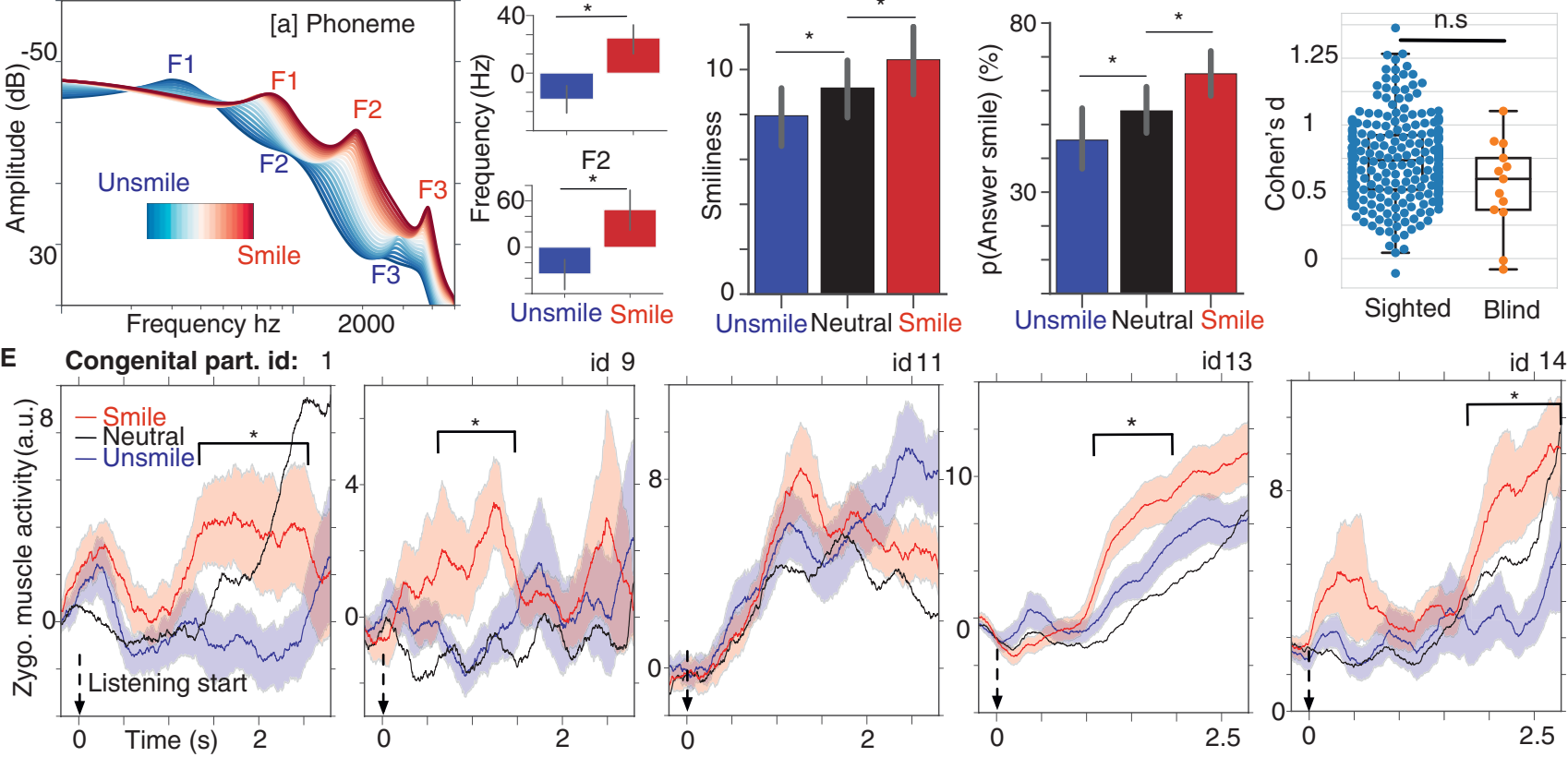

Figure 1. Controlling and perceiving auditory smiles.

(A) Audio manipulation example of an [a] phoneme, where can be seen the formant movements from the unsmile (blue) to the smile transformation (red) (B) Formant analysis of the stimuli for both unsmile (blue) and (smile) manipulations; Formants were normalised by the non-manipulated (neutral) sound; asterisks indicate significant differences between the distributions; error bars are $95 \%$ confidence intervals. (C) Mean smiliness rating (left) and decoding accuracy (right) for unsmile, neutral and smile transformations. (D) Difference in smile detection accuracy between sighted and blind participants. Each point represents the Cohen's d for an individual participant, computed using smile and unsmile rating distributions (rating task). Sighted participant data were simulated using a previously collected datase ${ }^{6}$, see Supplemental Information. Welsh's unequal variance t-test (13.0) $=1.95, p=0.07$; n.s., not statistically significant (see Supplemental Information). (E) Zygomatic activity for congenitally blind participants during the listening of the stimuli for smile (red), neutral (black) and unsmile (blue) conditions; Shaded areas represent SEM; Asterisks indicate significant differences between smile and unsmile time series $(p<0.05)$. 


\section{CellPress}

\section{Current Biology Magazine}

As a manipulation check, the acoustic manipulation significantly affected participants' impression of speaker's smiliness both in the rating $\left(\chi^{2}(11)=\right.$ 16.46, $\mathrm{p}=0.0003$ ) and in the detection task $\left(\chi^{2}(5)=35.1, p=2.38 \times 10 e^{-8}\right.$; Figure 1C; Supplemental Information). Individual statistics confirmed that blind participants significantly recognised the auditory signature of smiles in stimuli (congenital: 4/5, 80\%; early: 6/6, 100\%; late: $1 / 3$, 33\%; all: 11/14, 79\%; Supplemental Information). Smiledetection accuracy was comparable with that of previously tested ${ }^{6}$ sighted controls (Welsh's unequal variance t-test $\mathrm{t}(13.0)$ $=1.95, p=0.07$, Figure 1D, Supplemental Information).

We then analysed the difference between smile and unsmile EMG activity with Generalized Linear Mixed Models (GLMMs), combining data from both tasks, and found clear evidence of facial mimicry at the group level across all blind participants. For the zygomatic muscle, we found a main effect of the sound manipulation $\left(x^{2}(1)=4.56, p=0.03\right)$. The smile manipulation significantly increased zygomatic activity by 1.14 ( \pm 0.5 SE, $p$ $=0.03$ ) when compared to the unsmile effect. Conversely, for the corrugator muscle, the smile manipulation decreased muscle activity, although the difference was not significant $\left(X^{2}(1)=1.4\right.$, $\mathrm{p}=0.24$; see Supplemental Information for in-depth analysis of each task; Supplemental Data S1E).

To investigate the case of congenital participants specifically, we then analysed the EMG time series with individual statistics. We used the 240 time-series for each participant and each muscle and cluster permutation tests ${ }^{7}$. We found 10 clusters differentiating smile and unsmile EMG time series, all of which were congruent with the acoustic manipulation (four for the zygomatic muscle; six for the corrugator muscle, $p$ $<0.05$; Figure S1 and Figure S2 in the Supplemental Information; Supplemental Data S1F). Across the blind group, both the number of significant clusters, and their effect sizes, did not differ from sighted controls (Supplemental Information; Supplemental Data S1G). Crucially, significant clusters of congruent muscle activity were present in $4 / 5(80 \%)$ of our congenitally blind participants (Figure 1E).

In sum, we present here robust, replicated evidence that congenitally blind individuals are not only able to recognise smiling speakers from the sound of their voice, but also to implicitly mirror these smiles in their own facial expression in a similar manner to sighted individuals. The fact that our participants recognized auditory smiles is in contrast with the fact that blind individuals generally have difficulty recognizing emotions from vocal tones ${ }^{8}$. This suggests that, contrary to prosody, learning 'how smiles sound' does not heavily rely on the availability of contextual information about the faces of one's conversation partners, perhaps because their acoustic signature affords more direct inferences about a speaker's oro-facial configuration than does a given contour of pitch or loudness ${ }^{6}$.

More importantly, while it is known that congenitally blind individuals have preserved abilities to produce smiles and other facial expressions of emotions ${ }^{8}$, the fact that they do so spontaneously in response to auditory smiles constitutes striking evidence of facial mimicry in participants who, yet, have never seen a facial expression. While there is debate on whether facial imitative behavior develops on the basis of learned or innate associations ${ }^{2}$, most theories of imitation place visual observation as a core building block of imitative mechanisms ${ }^{4,9}$. Here, the fact that congenitally blind participants imitate smiles heard in speech conclusively demonstrates that the mechanisms of facial mimicry in fact do not require visual learning to develop.

How, then, did this capacity emerge? Consistent with the associative learning view $^{4}$, it is possible that, for blind individuals, auditory-motor associations heard in vocalizations and experienced in one's own proprioception provide a non-visual route for learning to perceive and produce facial expressions of emotion. In the alternative innate view, it is also possible that these associations do not require learning and are built in the system, either in the form of cortical mirror mechanisms ${ }^{9}$ or of prewired emotional responses taking input from phylogenetically-ancient, multimodal (visual-auditor-motor) subcortical structures $^{10}$.

In either case, the present results demonstrate that imitation is not a mere visuo-motor process, but rather a flexible mechanism deployed across sensory inputs, able to map cross- modal exteroceptive signals to their corresponding motor representations and socially appropriate responses.

\section{SUPPLEMENTAL INFORMATION}

Supplemental Information includes experimental procedures, analyses, two figures, one data file and can be found with this article online at https://doi.org/10.1016/j.cub.2021.08.059.

\section{ACKNOWLEDGMENTS}

The authors thank Lou Seropian and Pilar Rios for help with data collection. Experimental data collected at INJA (National Institute for Blind Youth) with support from the INSEAD/Sorbonne University Centre for Behavioural Science. Work funded by ERC StG CREAM 335536, ANR REFLETS and SEPIA, as well as support from Fondation pour l'Audition FPA RD-2018-2 (to JJ.A.), and the Swedish Research Council (2014-1371) to P.A.

\section{REFERENCES}

1. Frith, C.D., and Frith, U. (2012). Mechanisms of social cognition. Annu. Rev. Psychol. 63, 287-313.

2. Oostenbroek, J., Suddendorf, T., Nielsen, M., Redshaw, J., Kennedy-Costantini, S., Davis, J., Clark, S., and Slaughter, V. (2016). Comprehensive longitudinal study challenges the existence of neonatal imitation in humans. Curr. Biol. 26, 1334-1338.

3. Kaiser, J., Crespo-Llado, M.M., Turati, C., and Geangu, E. (2017). The development of spontaneous facial responses to others' emotions in infancy: An EMG study. Sci. Rep. 7, 17500.

4. Heyes, C. (2016). Homo imitans? Seven reasons why imitation couldn't possibly be associative. Phil. Trans. R. Soc. Lond. B 371, 20150069.

5. Tartter, V.C. (1980). Happy talk: Perceptual and acoustic effects of smiling on speech. Attent. Percept. Psychophys. 27, 24-27.

6. Arias, P., Belin, P., and Aucouturier, J.-J. (2018). Auditory smiles trigger unconscious facial imitation. Curr. Biol. 28, R782-R783.

7. Maris, E., and Oostenveld, R. (2007) Nonparametric statistical testing of EEG-and MEG-data. J. Neurosci. Meth. 164, 177-190.

8. Valente, D., Theurel, A., and Gentaz, E. (2018). The role of visual experience in the production of emotional facial expressions by blind people: a review. Psychon. Bull. Rev. 25, 766-774.

9. Meltzoff, A.N., and Marshall, P.J. (2018). Human infant imitation as a social survival circuit. Curr. Opin. Behav. Sci. 24, 130-136.

10. Johnson, M.H. (2005). Subcortical face processing. Nat. Rev. Neurosci. 6, 766-774.

\section{'STMS Lab (IRCAM/CNRS/Sorbonne} Université), 1 Place Igor Stravinsky, 75004 Paris, France ${ }^{2}$ Lund University Cognitive Science, Lund University, Box 192, 22100 Lund, Sweden. ${ }^{3}$ Institut National des Jeunes Aveugles, 56 Bd des Invalides, 75007 Paris, France. ${ }^{4}$ FEMTO-ST Institute (CNRS/Université Bourgogne Franche Comté), 15B Av. des Montboucons, 25000 Besançon, France. ${ }^{5}$ Lead contact.

*E-mail: pablo.arias.sar@gmail.com 
